\title{
Novel Polycarbonates via Phosgenation of Unsaturated Diols
}

\author{
Nayef S. Al-Muaikel \\ Chemistry Department, College of Science, Aljouf University, Aljouf, P.O. Box 643, Sakaka, Saudi Arabia \\ Abstract: A new interesting class of linear unsaturated polycarbonates based on methyl- cyclohexanone and 4-tert. \\ butyl- cyclohexanone moieties has been synthesized. An interfacial phosgenation technique carried out at ambient \\ temperature was used for the synthesis of these polycarbonates. The resulting polycarbonates were characterized by \\ elemental analyses, infrared spectroscopy, ${ }^{1} \mathrm{H}$ nuclear magnetic resonance spectral analyses, viscometry, differential \\ scanning calorimetry and thermogravimetric analysis measurements. All the polycarbonates were soluble in polar \\ solvents like dimethylsulphoxide and sulphuric acid. The crystallinity of some selected polycarbonates was examined by \\ X-ray analysis. In addition, the morphology of selected examples of the polycarbonates was examined by scanning \\ electron microscopy.
}

Keywords: Characterization, Synthesis, polycarbonates, Polycondensation, Unsaturated Diols.

\section{INTRODUCTION}

Polycarbonates (PC) are linear and thermoplastic polyesters of carbonic acid [l-3]. For some time polycarbonates based on bisphenol $A$ have been produced commercially by Farbenfabriken Bayer in Germany and General Electric in the United States under the trade names of Lexan and Merlon respectively. Polycarbonate (PC) showed appealing features and unique applications in our daily life. They are employed in several fields such as transparent and rigid support for CD, DVD or other metals reflecting surfaces, in medical applications, as dome light or curved roofing in building industry [4]. Several varieties of PC are available, obtained from different carbonate precursors (phosgene or diphenyl carbonate) and bisphenol monomers and the largely used monomer is 2,2-bis(4,4'-hydroxyphenyl)propane (1), also known as bis phenol-A (BPA) [4]. PC widespread large use and it is expected, over the period 2013-2018, a further grow of the global polycarbonate market [5]. Many recycling issues of end-life PC item are proposed and three main paths may be followed: mechanical, chemical, and thermochemical recycling [6]. Following mechanical recycling, PC is separated from other materials (i.e. labels, metals, or other inert materials), and then neat PC is grinded, melted and reprocessed. However, a drop in mechanical and physical properties is always observed and to restore the performance of final product a blending with virgin $\mathrm{PC}$ is required $[6,7]$. Furthermore this procedure can not be followed for contaminated PC.

The work reported here outlines the synthesis of polycarbonates via interfacial phosgenation technique

*Address correspondence to this author at the Chemistry Department, College of Science, Aljouf University, Aljouf, P.O. Box 643, Sakaka, Saudi Arabia; E-mail: n_almuaikel@hotmail.com at ambient temperature. A major target of this work was to study the effect of the substituted cycloalkanone moiety upon the properties of polycarbonates polymers, including their thermal stability, solubility, morphology and crystallinity.

\section{EXPERIMENTAL}

\subsection{Measurements}

Elemental analyses were carried out using an Elemental Analyses system $\mathrm{GmbH}$, VARIOEL, $\mathrm{V}_{2.3}$ July 1998 CHNS Mode. IR spectra were recorded on IR470, Infrared spectrophotometer, Shimadzu by using the $\mathrm{KBr}$ pellet technique. The ${ }^{1} \mathrm{H}$-NMR spectra were recorded on a GNM-LA 400-MHz NMR spectrophotometer at room temperature in DMSO or $\mathrm{CDCl}_{3}$ using TMS as the internal reference.. Inherent viscosities of polymer solutions $(0.5 \% \mathrm{w} / \mathrm{v})$ in DMSO were determined at $30{ }^{\circ} \mathrm{C}$ using an Ubbelohde suspended level viscometert. The solubility of polymers was examined using $0.02 \mathrm{~g}$ of polymer in $3-5 \mathrm{ml}$ of solvent at room temperature. The X-ray diffractographs of the polymers were obtained with a Philips X-ray PW1710 diffractometer, and $\mathrm{Ni}$ - filtered CuK $\alpha$ radiations. Pellets for electrical conductivity measurements were prepared by pressing at a constant pressure of 1000 psi using an IR die. Silver paste was used to make contacts between the polymer pellets and two graphite electrodes. Conductivities were measured at room temperature in air using a 610 ${ }^{\circ} \mathrm{C}$ Keithley electrometer. Thermogravimetric analysis (TGA) and differential thermal gravimetric (DTG) were carried out in air with Shimadzu DTG-60 at heating rate of $10^{\circ} \mathrm{C} / \mathrm{min}$. in air. The morphology of a selected example of polycarbonate II was examined by SEM(Jeol JSM-5400 LV instrument). The SEM sample was prepared by evaporating a dilute solution of 
polymer on a smooth surface of aluminium foil, and subsequently coating it with gold palladium alloy. SEM images were taken on a Pentaz Z-50 P Camera with Ilford film at an accelerating voltage of $15 \mathrm{KV}$ using a low dose technique [8].

\subsection{Reagents and Solvents}

Tert.butyl-cyclohexanone (Merck, 99\%). Methylcyclohexanone (Merck, 99\%) were used without purification. Triphosogene (Aldrich, $98 \%$ ) m.p. $79-83^{\circ} \mathrm{C}$ was also used without purification. All other reagents were of high purity and were further purified as reported in literature [9].

\subsection{Monomer Synthesis}

\section{i) Synthesis of 2,6-Bis(p-hydroxybenzylidene) methyl- cyclohexanone I}

A mixture of (2.44 g, 0.2 mole) 4-hydroxybenzaldehyde and (1.11 g, 0.1 mole) methylcyclohexanone was dissolved in $100 \mathrm{ml}$ ethanol at $50^{\circ} \mathrm{C}$. The mixture was stlrrred while dry $\mathrm{HCl}$ gas was introduced as a catalyst. After two hrs of stirring, a solid product separated out, which was filtered off, washed with excess water, dried and recrystallized twice from methanol as greenish yellow crystals; yield: $94.5 \%$; m.p.: $158{ }^{\circ} \mathrm{C}$. Anal. Calcd. for $\mathrm{C}_{21} \mathrm{H}_{19} \mathrm{O}_{3}: \mathrm{C}, 78.99 ; \mathrm{H}$, 5.96. Found: $\mathrm{C}, 78.43 ; \mathrm{H}, 5.63$.

\section{ii) Synthesis of 2,6-divanillylidene metyl. cyclohexanone II}

A mixture of (3.04 g, 0.2 mole) 4-hydroxy-3methoxybenzaldehyde and (1.11 g, 0.1 mole) methyl. cyclohexanone was dissolved in $100 \mathrm{ml}$ ethanol at $50^{\circ} \mathrm{C}$. The mixture was stlrrred while dry $\mathrm{HCl}$ gas was introduced as a catalyst. After two hrs of stirring, a solid product separated out, which was filtered off, washed with excess water, dried and recrystallized twice from methanol as greenish yellow crystals; yield: 94.5\%; m.p.: $142{ }^{\circ} \mathrm{C}$. Anal. Calcd. for $\mathrm{C}_{23} \mathrm{H}_{23} \mathrm{O}_{5}: \mathrm{C}, 72.82 ; \mathrm{H}$, 6.07. Found: $\mathrm{C}, 72.43 ; \mathrm{H}, 5.83$.

iii) Synthesis of 2,6-Bis(p-hydroxybenzylidene) tert. but. cyclohexanone III

A mixture of (2.44 g, 0.2 mole) 4-hydroxybenzaldehyde and (1.54 g, 0.1 mole) tert. but. cyclohexanone was dissolved in $100 \mathrm{ml}$ ethanol at $50^{\circ} \mathrm{C}$. The mixture was stlrrred while dry $\mathrm{HCl}$ gas was introduced as a catalyst. After two hrs of stirring, a solid product separated out, which was filtered off, washed with excess water, dried and recrystallized twice from methanol as greenish yellow crystals; yield: $94.5 \%$; m.p.: $120-121^{\circ} \mathrm{C}$. Anal. Calcd. for $\mathrm{C}_{21} \mathrm{H}_{20} \mathrm{O}_{5}$ : C, 71.58; $H, 5.72$. Found: $C, 71.43 ; H, 5.63$.

\section{iv) Synthesis of 2,6-divanillylidene tert. but. cyclohexanone IV}

A mixture of (3.04 g, 0.2 mole) 4-hydroxy-3methoxybenzaldehyde and ( $1.54 \mathrm{~g}, 0.1$ mole) tert. but. cyclohexanone was dissolved in $100 \mathrm{ml}$ ethanol at $50^{\circ} \mathrm{C}$. The mixture was stirred while dry $\mathrm{HCl}$ gas was introduced as a catalyst. After two hrs of stirring, a solid product separated out, which was filtered off, washed with excess water, dried and recrystallized twice from methanol as greenish yellow crystals; yield: $94.5 \%$; m.p: $108-109{ }^{\circ} \mathrm{C}$. Anal. Calcd. for $\mathrm{C}_{21} \mathrm{H}_{20} \mathrm{O}_{5}$ : C, 71.58; $H, 5.72$. Found: $C, 71.43 ; H, 5.63$.

\subsection{Polymerization Procedure}

In a three-necked round-bottomed flask $\left(500 \mathrm{~cm}^{3}\right.$ in volume), equipped with a mechanical stirrer (2000 rev $\min ^{-1}$ ), dry nitrogen inlet and outlet, and dropper, a mixture (3 mmol) of the appropriate diarylidenecycloalkanones derivatives (I-IV) (see

Table 1: Elemental Analyses, Inherent Viscosity and Yield of Polycarbonates V-VIII

\begin{tabular}{|c|c|c|c|c|c|c|c|}
\hline \multirow{2}{*}{$\begin{array}{c}\text { Polymer } \\
\text { Code }\end{array}$} & \multirow{2}{*}{ Repeating unit } & \multicolumn{2}{|c|}{$\mathrm{C} \%$} & \multicolumn{2}{|c|}{$\mathrm{H} \%$} & \multirow{2}{*}{$\begin{array}{c}\eta_{\operatorname{lnh}} \\
(\mathrm{dl} / \mathrm{g})\end{array}$} & \multirow{2}{*}{$\begin{array}{c}\text { Yield } \\
(\%)\end{array}$} \\
\hline & & Calcd. & Found & Calcd. & Found & & \\
\hline $\mathrm{V}$ & $\begin{array}{c}\mathrm{C}_{22} \mathrm{H}_{17} \mathrm{O}_{4} \\
(345)\end{array}$ & 76.52 & 75.98 & 4.93 & 4.37 & 0.79 & 75 \\
\hline VI & $\begin{array}{c}\mathrm{C}_{24} \mathrm{H}_{21} \mathrm{O}_{6} \\
(405)\end{array}$ & 71.11 & 70.16 & 5.19 & 5.02 & 0.52 & 85 \\
\hline VII & $\begin{array}{c}\mathrm{C}_{25} \mathrm{H}_{23} \mathrm{O}_{4} \\
(387)\end{array}$ & 77.52 & 76.83 & 5.94 & 5.08 & 0.63 & 79 \\
\hline VIII & $\begin{array}{c}\mathrm{C}_{27} \mathrm{H}_{27} \mathrm{O}_{6} \\
(447)\end{array}$ & 72.48 & 71.32 & 6.04 & 5.56 & 0.88 & 80 \\
\hline
\end{tabular}

${ }^{*} \eta$ Inherent viscosity measured in DMSO at $30^{\circ} \mathrm{C}$ 
Scheme 1 below), $30 \mathrm{ml}$ of methylene chloride and a suitable quantity of sodium hydroxide $(4 \mathrm{mmol}$ soluble in $30 \mathrm{ml}$ of water) were introduced. After mixing, 1.5 mmol of triphosgene dissolved in $30 \mathrm{ml}$ dry methylene chloride was added carefully in one portion at room temperature and vigorously stirred. After completing the addition of the triphosgene, stirring was continued for $1 \mathrm{~h}$ until a very yellow solid separated out.

The solid polycarbonates was filtered off, washed with water, dilute acetic acid and alcohol, and dried under reduced pressure $(1 \mathrm{mmHg})$ at $60^{\circ} \mathrm{C}$ for $24 \mathrm{~h}$. Table 1 summarizes yield, elemental analysis and electrical properties of the polycarbonates.

\section{RESULTS AND DISCUSSION}

A new and unreported class of linear unsaturated polycarbonates based on cyclohexanone derivatives were synthesized via phosgenation (using triphosgene) of 2,6-bis(p-hydroxybenzylidene) methylcyclohexanone I or 2,6-divanillyidene methylcyclohexanone II , 2,6-bis(p-hydroxybenzylidene) tert. but. cyclohexanone III or 2,6-divanillyidene tert. but. cyclohexanone IV using an interfacial polycondensation technique. The synthesis of the monomers I-IV is represent in Scheme 1, while Scheme 2 represent the synthesis of polycarbonates.

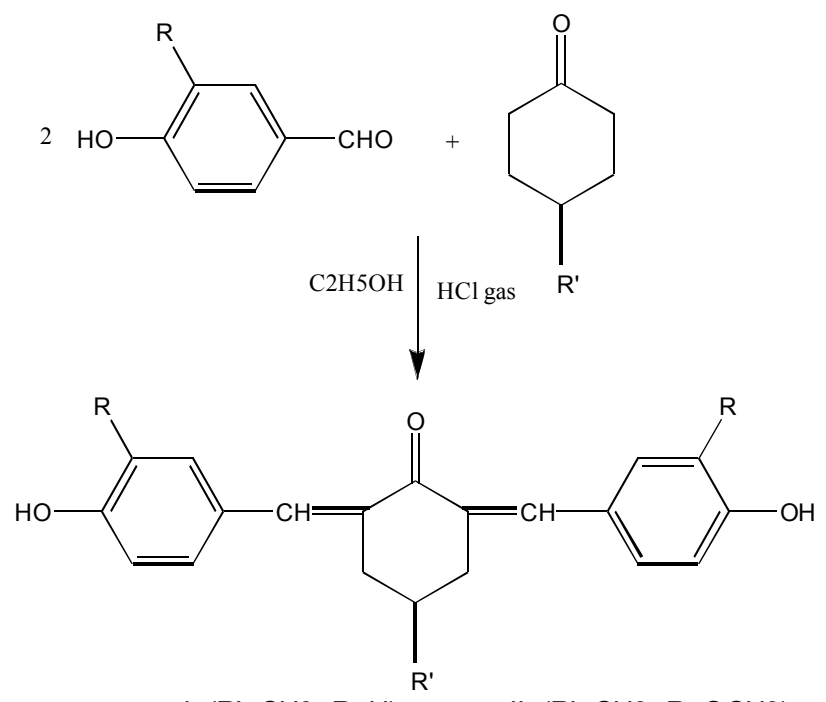

I: (R'=CH3, R=H); II: $\left(\mathrm{R}^{\prime}=\mathrm{CH} 3, \mathrm{R}=\mathrm{OCH} 3\right)$;

III: (R'=isopropyl, R=H); IV: (R'=isopropyl, R=OCH:

Scheme 1: Synthesis of Monomers I-IV.

The structure of the resulting polymers was also established from elemental and spectral analyses, FTIR spectra, IH-NMR analysese. The elemental analyses of all the polycarbonates coincided with the characteristic repeating units of each polymer, the data

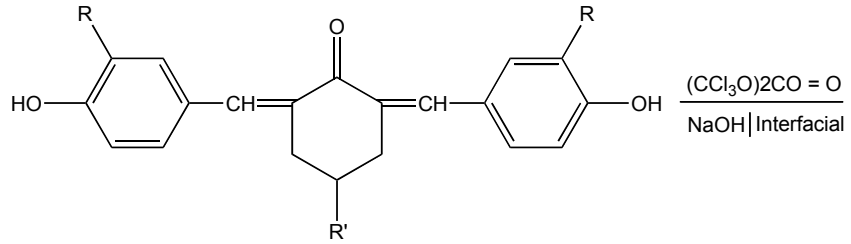

I: $\left(\mathrm{R}^{\prime}=\mathrm{CH}_{3}, \mathrm{R}=\mathrm{H}\right) ; \quad$ II: $\left(\mathrm{R}^{\prime}=\mathrm{CH}_{3}, \mathrm{R}=\mathrm{OCH}_{3}\right)$; III: ( $\mathrm{R}^{\prime}=$ isopropyl, $\left.\mathrm{R}=\mathrm{H}\right)$; IV: $\left(\mathrm{R}^{\prime}=\right.$ isopropyl, $\left.\mathrm{R}=\mathrm{OCH}_{3}\right)$.

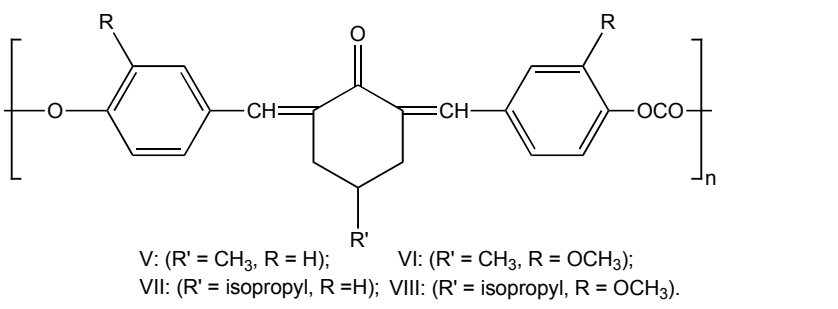

Scheme 2: Synthesis of Polycarnoates V-VIII.

are included in Table 1. It should be noted that the elemental analyses of these polymers deviated up to $1.46 \%$ from the theoretical values. However, it is not uncommon for polymers to trap solvent molecules within the polymer matrix, especially polymers of high molecular weight and those polymers containing polar groups which are capable of hydrogen bonding with solvent molecules $[10,11]$.

The FT-IR spectra of all the polycarbonates showed the disappearance of the hydroxyl groups and the appearance of absorption bands at $1750-1765 \mathrm{~cm}^{-1}(\mathrm{C}$ $=\mathrm{O}$ of carbonates), at $1665-1685 \mathrm{~cm}^{-1} \quad(\mathrm{C}=\mathrm{O}$ of cyclohexanone moiety), at $1580-1600 \mathrm{~cm}^{-1}$ ( $\mathrm{C}=\mathrm{C}$ stretching), at $1150-1250 \mathrm{~cm}^{-1}$ (ester of $\mathrm{C}=\mathrm{O}$ stretching vibrations and out of plane $\mathrm{CH}$ deformation vibrations of paradisubstituted phenyl), and at 1010 and $815 \mathrm{~cm}^{-1}$ (out of plane $\mathrm{CH}$ deformation vibrations of paradisubstituted phenyl).

${ }^{1} \mathrm{H}-\mathrm{NMR}(\mathrm{S} / \mathrm{CDCl}$,) for polycarbonate $\mathrm{V}$ showed at $7.68 \mathrm{ppm}(\mathrm{s}, 2 \mathrm{H}$ of $\mathrm{CH}=\mathrm{C})$, at 6.75-7.32 pprn $(\mathrm{m}, 6 \mathrm{H}$ of $\mathrm{Ar}-\mathrm{H})$, at $3.75 \mathrm{ppm}\left(\mathrm{S}, 6 \mathrm{H}\right.$ of $\left.2 \mathrm{OCH}_{3}\right)$, at $2.74 \mathrm{ppm}$ (d, $4 \mathrm{H}, 2 \mathrm{CH} 2$ of cyclohexanone), and at 1.77-2.1 ppm (pented, $2 \mathrm{H}, \mathrm{CHz}$ of cyclohexanone).

\section{Polymer Characterization}

The various characteristics of the resulting polycarbonates including: solubility, viscosimetry, electronic spectra, X-ray diffraction analysis, morphology, thermal behavior and electrical properties were also determined and the data were discussed .

\section{Viscosity}

The inherent viscosities $\left(\eta_{\text {inh }}\right)$ of polycarbonates $V$ VIII were determined in DMSO at $30^{\circ} \mathrm{C}$ with an 
Table 2: Solubility Characteristics of Polycarbonates V-VIII

\begin{tabular}{|c|c|c|c|c|c|c|c|c|}
\hline $\begin{array}{c}\text { Polymer } \\
\text { code }\end{array}$ & DMSO & $\begin{array}{c}\text { DMF-DMA } \\
(\mathbf{1}: 1)\end{array}$ & NMP & $\begin{array}{c}\text { Chloroform } \\
\text { Acetone } \\
(\mathbf{1 : 1})\end{array}$ & $\begin{array}{c}\text { THF } \\
\text { Methylene } \\
\text { chloride }\end{array}$ & $\begin{array}{c}\mathrm{H}_{2} \mathrm{SO}_{4} \\
\begin{array}{c}\text { Electrical } \\
\text { Conductivity } \\
\left(\Omega \mathrm{cm}^{-1}\right)\end{array}\end{array}$ \\
\hline \hline $\mathrm{V}$ & + & \pm & \pm & - & - & \pm & + & $3.9 \times 10^{-11}$ \\
\hline $\mathrm{VI}$ & + & \pm & \pm & - & - & + & + & $6.5 \times 10^{-12}$ \\
\hline $\mathrm{VII}$ & + & + & + & \pm & \pm & + & + & $1.2 \times 10^{-12}$ \\
\hline $\mathrm{VIII}$ & + & + & + & \pm & \pm & + & + & $3.5 \times 10^{-13}$ \\
\hline
\end{tabular}

(+) Soluble at room temperature RT.

$( \pm)$ Partially soluble at RT.

(-) Insoluble.

Ubbelohde suspended level viscometer The inherent viscosity value is defined as:

$$
\eta_{\text {inh }}=\left[2.3 \log \eta / \eta_{\mathrm{o}}\right] / C
$$

The solution concentration $\mathbf{C}$ is $0.5 \mathrm{~g} / 100 \mathrm{ml}, \mathrm{\eta} / \eta_{0}=$ relative viscosity (or viscosity ratio). It can be shown from Table 1 that polycarbonate VIII had high inherent viscosity $(0.88 \mathrm{dL} / \mathrm{g})$ and this may be attributed to high molecular weight of the polymer, while the inherent viscosity of the copolymer $\mathrm{VI}(0.55 \mathrm{dL} / \mathrm{g})$ this may be attributed to low molecular weight of this polymer.

\section{Solubility}

The solubility characteristics of the polycarbonates are shown in Table 2. A $10 \%(\mathrm{w} / \mathrm{v})$ solution was taken as a criterion for solubility. It was found that all the polycarbonates dissolved readily in concentrated $\mathrm{H}_{2} \mathrm{SO}_{4}$ at room temperature giving an intense red solution. Polycarbonates which contain tert. butyl. Cyclohexanone moiety $\mathrm{C}\left(\mathrm{CH}_{3}\right)_{3}$ (VII. VIII) are more soluble in DMSO or NMP more than those which contain the methyl- cyclohexanone and less polar solvents, including ; acetone- chloroform mixture and THF except copolythioesters, VIII and IX were partially soluble in less polar solvents. Generally, the presence of carbonate groups in the polymer main chain led to slight increases in the solubility of the polycarbonates. It should be noted that a change in the pendant groups along the polymer chain led to a pronounced difference in the solubility of the prepared polymers.

\section{Electronic Spectra}

The electronic spectra of Polycarbonates V-VIII were obtained in DMSO at a concentration of $2.6 \times 10-6$ M. These displayed two absorption bands with Imax near $263 \mathrm{~nm}$, which was due to the $\pi-\pi{ }^{*}$ transition within the benzenoid system, and with $\lambda$ max near 369 $\mathrm{nm}$, which was due to the $\pi-\pi^{*}$ excitation of $\mathrm{C}=\mathrm{O}$ or $\mathrm{C}=\mathrm{C}$ groups. The electronic spectra of polycarbonates
V- VIII show broadening absorption bands and a small bathochromic shifting of both bands, indicating a highly conjugated system. Moreover, the electric conducting properties of the undoped and doped polymers are therefore related to the presence of extensively delocalized $p$ electrons along the polymer chain, and the delocalization of $\pi$ electrons also contributes to the formation of the polymer-iodine adducts.

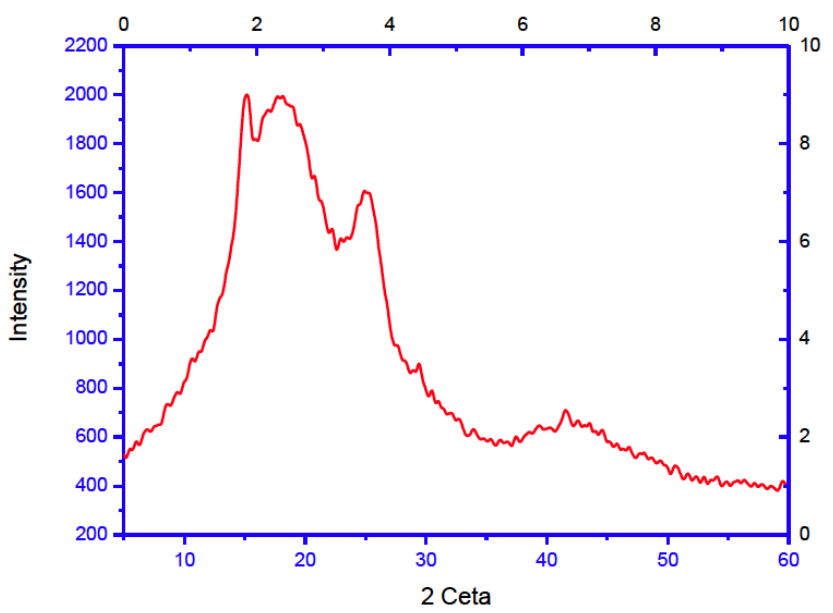

Figure 1: X-ray Diffraction pattern of Polycarbonate VI.



Figure 2: X-ray Diffraction pattern of Polycarbonate VIII. 


\section{$\underline{X-R a y ~ A n a l y s i s ~}$}

The X-ray diffractogram of Polycarbonates V-VIII containing 4-teriary butyl-cyclohexanone unit in Figures 1 and 2 (as example) show a few reflection peaks that are intermediate between crystalline and amorphous interference in the region $2 \theta=5-60^{\circ}$. This indicates that there is a large class of structures that are intermediate in the ordered states between crystals (with pronounced long-range order) in the arrangement of their atoms and molecules. Moreover, the presence of high $\mathrm{C}=\mathrm{C}$ bond and $\mathrm{C}=\mathrm{S}$ levels induces some order between two adjacent chains in the polymer, leading to some extent of crystallinity. The X-ray diffractographs in Figure 3 also show that polycarbonates which contain tert. But. cyclohexanone moiety $(\mathrm{V}$,$) have a$ high degree of crystallinity in comparison with those containing methyl-cyclohexanone (VIII).

\section{Scanning Electron Microscopy Measurements}

The morphology of the synthesized of selected examples of polycarbonates VII (as example) was examined by scanning electron microscopy (SEM). The

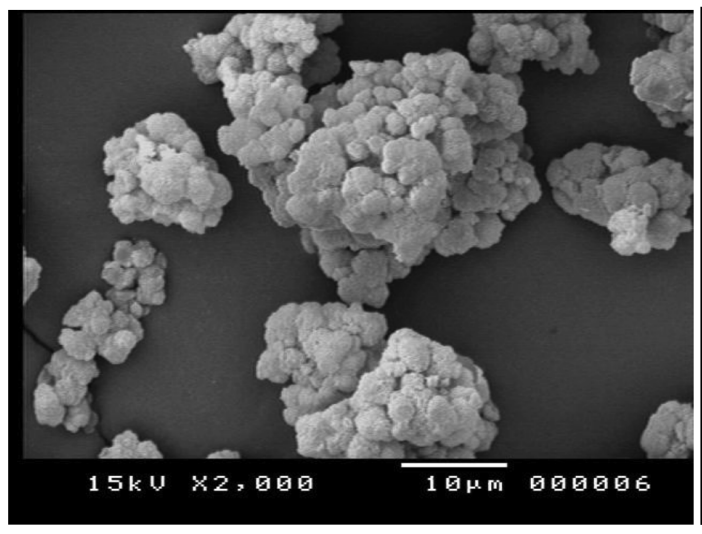

a

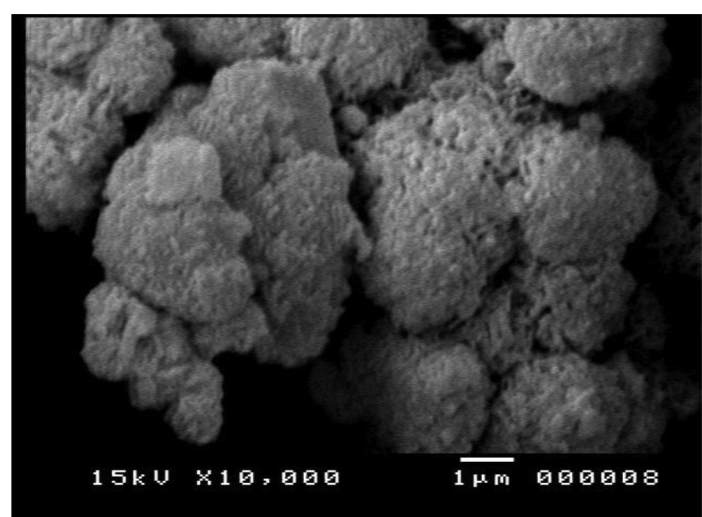

c

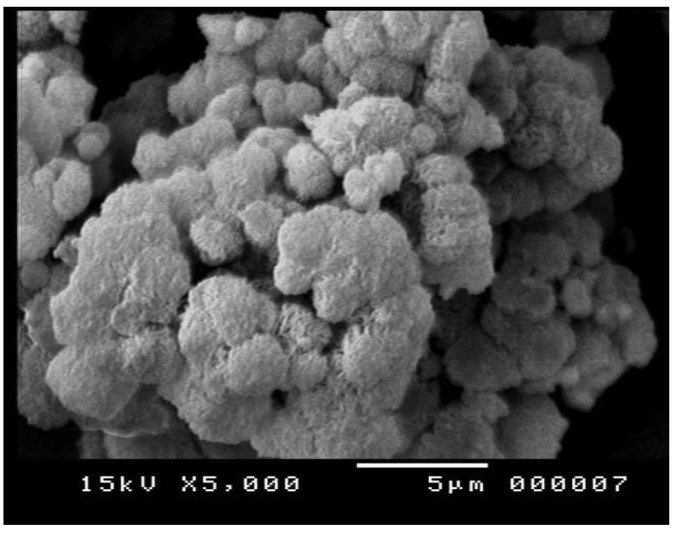

b

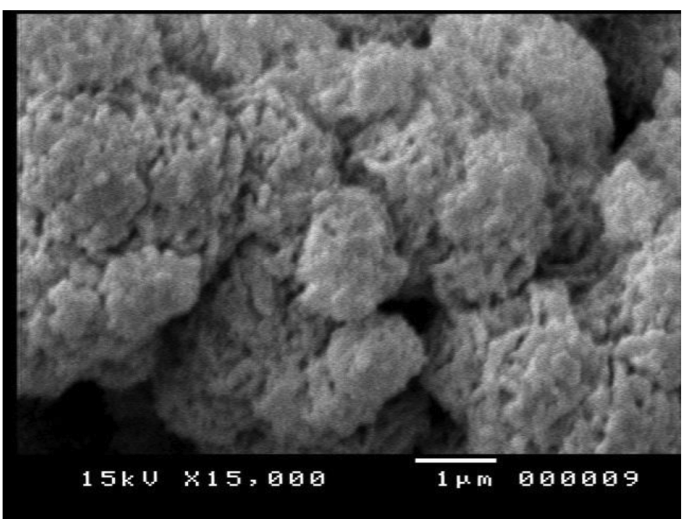

d

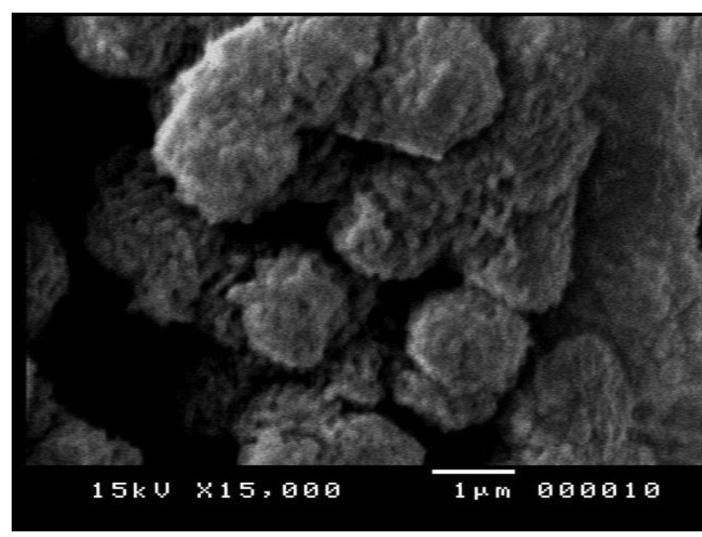

e

Figure 3: SEM images of Polycarbonates VI surface at different magnifications, $\mathbf{a}: \mathrm{x}=2000$; and $\mathbf{b}: \mathrm{x}=5000 ; \mathbf{c}$ : $\mathrm{x}=10,000$; and $\mathbf{d}: \mathrm{x}=15,000 ; \mathbf{e}: \mathrm{x}=15,000$. 
sample was prepared by putting a smooth part of polymer powder on a copper holder and subsequently coating it with gold palladium alloy. SEM images were taken on a penta Z Z-50 P Camera with Ilford film at an accelerating voltage of $15 \mathrm{Kv}$ using a low-dose technique [12]. This technique gives us the ability to show the surface of the polymers and to study the effect of structure on the surface of the selected polymer by comparison the images in each case. The study of selected polycarbonate VII showed that the surface of that polymer VII (Figure 3a, magnification X= 2000) consisted of porous kidney shape accumulative merged particles, with higher magnification $X=5000$, 10,000 (Figure $\mathbf{3 b}, \mathbf{c}$ ) showed grape fruit like shape. The higher magnification $X=15000$ (Figure 3d,e) showed that the globular and subglobular structures appeared in a continuous chain with some coalescence present.

\section{Thermogravimetric Analysis}

The thermal behaviour of polycarbonates V-VIII, containing 4-teriary butyl-cyclohexanone or methylcyclohexanone moieties thus obtained were investigated with the aids of thermogravimetric analysis (TGA), DTG and DTA in Nitrogen at a heating rate of $10^{\circ} \mathrm{C} / \mathrm{min}$. TGA curves of polycarbonates are given in Figures $\mathbf{4}$ and $\mathbf{5}$, also Table $\mathbf{3}$ gives the temperature of various percentages of weight loss. The initial decomposition of these polymers $(10 \%$ loss $)$ is considered to be the polymer decomposition temperature (PDT) $[13,14]$ it occurred in the range 215 ${ }^{\circ} \mathrm{C}$ to $239^{\circ} \mathrm{C}$ for the synthesized polyamides. In Figure 4, TGA curve of polycarbonate VI showed four steps for the polymer degradation: The first step started from 19.26-128.22 ${ }^{\circ} \mathrm{C}$, weight loss from 0.063 to $1.65 \%$; which may be attributed to loss of absorbed moisture and entrapped solvents; the second step started from 130.86 to $107.88{ }^{\circ} \mathrm{C}$, weight loss from 0.374 to 9.824 $\%$; the third step started from 309.49 to $461.71{ }^{\circ} \mathrm{C}$, weight loss 1.371 to $36.013 \%$; and finally the fourth step (last step) started from 463.69 to $597.42{ }^{\circ} \mathrm{C}$, weight loss 1.349 to $35.435 \%$. The rate of degradation in the third stage is somewhat faster than in the other stages. In Figure 5, TGA curve of polycarbonate VIII showed three steps for the polymer degradation: The first step started from 32.37 to $245.95{ }^{\circ} \mathrm{C}$, weight loss from 0.161 to $6.164 \%$; which may be attributed to loss of absorbed moisture and entrapped solvents; the second step started from 247.89 to $441.44{ }^{\circ} \mathrm{C}$, weight loss from 1.017 to $38.936 \%$; and the third step started from 443.38 to $595.57^{\circ} \mathrm{C}$, weight loss 1.465 to 56.087 $\%$. The rate of degradation in the third stage is somewhat faster than in the first or second stages. Moreover, the data indicated that the polycarbonate $\mathrm{V}$ is more thermally stable than the polycarbonate VII and this may be attributed to the presence isopropyl group in the polymer main chain in the later polycarbonate, and this decrease the stability.

The electrical conductivity of the polycarbonates was measured by the Arrhenius method and gave values in the range $10^{-11}-10^{-13}\left(\Omega \mathrm{cm}^{-1}\right)$ (see Table 1 ).

\section{CONCLUSIONS}

Novel Polycarbonates based on diarylidenecycloalkanone derivatives have been

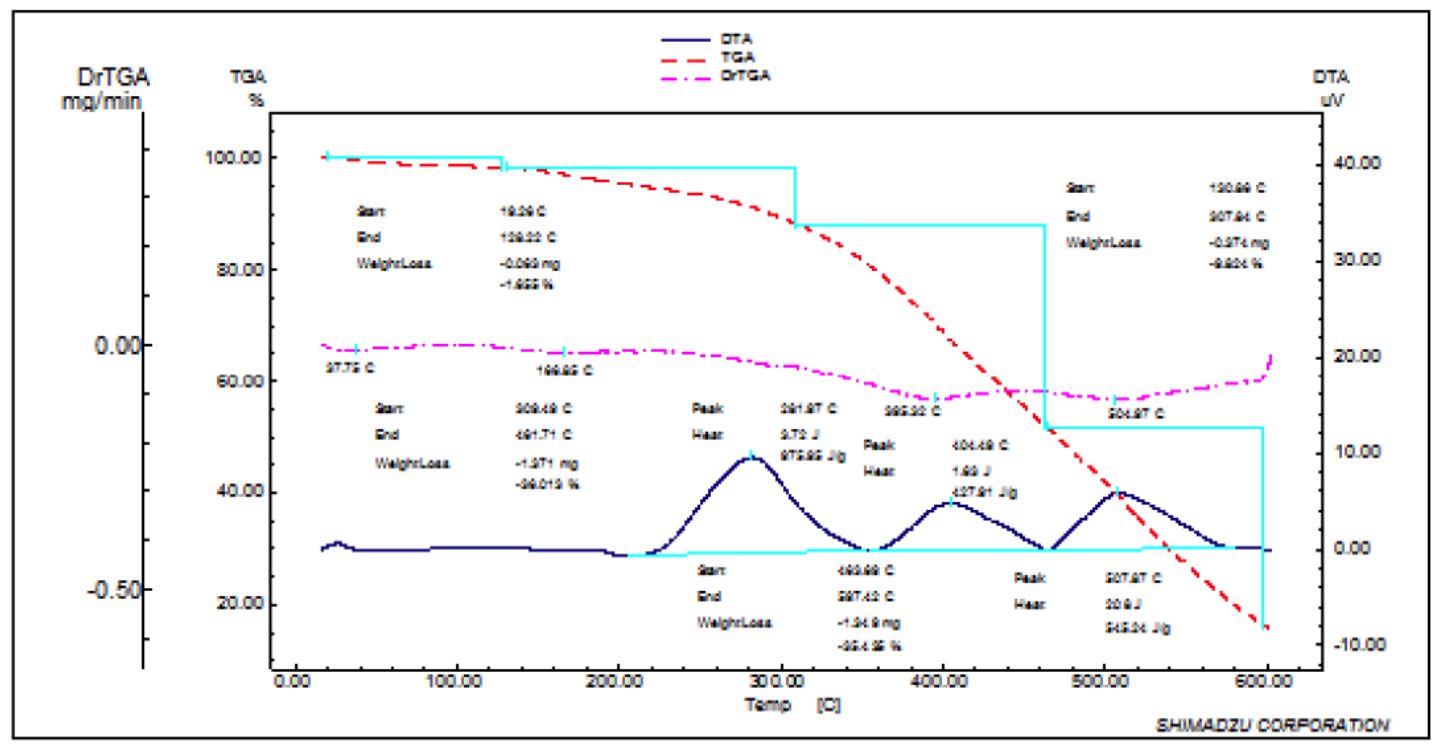

Figure 4: The TGA and Dr TGA traces of Polycarbonates VI in nitrogen at a heating rate of $10^{\circ} \mathrm{C} / \mathrm{min}$. 


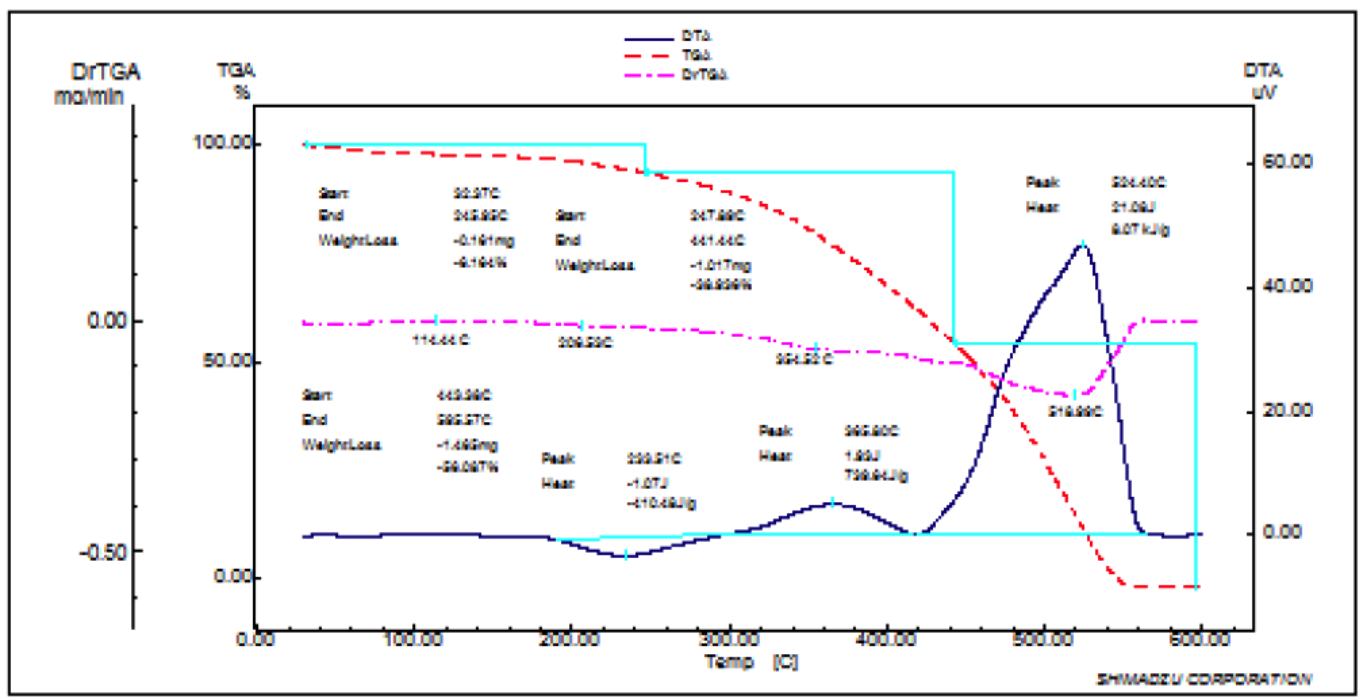

Figure 5: The TGA and Dr TGA traces of Polycarbonates VIII in nitrogen at a heating rate of $10^{\circ} \mathrm{C} / \mathrm{min}$.

Table 3: Thermal Properties of Polycarbonates V-VIII

\begin{tabular}{|c|c|c|c|c|c|}
\hline \multirow{2}{*}{$\begin{array}{l}\text { Polymer } \\
\text { Code }\end{array}$} & \multicolumn{5}{|c|}{ Temperature $\left({ }^{\circ} \mathrm{C}\right)$ for various decomposition levels } \\
\hline & $10 \%$ & $20 \%$ & $30 \%$ & $40 \%$ & $50 \%$ \\
\hline $\mathrm{V}$ & 310 & 350 & 395 & 425 & 460 \\
\hline VI & 305 & 355 & 405 & 430 & 455 \\
\hline VII & 295 & 330 & 385 & 450 & 450 \\
\hline VIII & 280 & 305 & 350 & 390 & 420 \\
\hline
\end{tabular}

*Heating rate: $10^{\circ} \mathrm{C} \mathrm{min}^{-1}$.

synthesized. An interfacial phosgenation technique at ambient temperature was used. The majority of the polycarbonates were soluble in halogenated solvents. X-ray diffraction analyses showed that the new polycarbonates has some degree of crystallinity. Thcrmogravimetric analyses showed that polycarbonate VIII, was somewhat less thermally stable than the others. SEM examination of polycarbonates VII revealed that the polycarbonates under study possess a globular and subglobular structures. Moreover, the electrical conductivity measurements indicated that all the polycarbonates are insulator materials.

\section{REFERENCES}

[1] Jadhav JY, Preston J, Krigbaum WR. Aromatic rigid chain copolymers. I. Synthesis, structure, and solubility of phenylsubstituted para-linked aromatic random copolyamides. J Polym Sci Part A: Polym Chem 1989; 27: 1175-95. http://dx.doi.org/10.1002/pola.1989.080270407

[2] Schnell H, Chemistry and Physics of Po!ycarbonates, Wiley Interscience, New York 1964.

[3] Vemaleken $\mathrm{H}$, in Interfacial Syntheru (F. Alillich and C.E. Carreher, Jr., Eds), Marcel Dekker, New York 1975.
[4] Serini V, in Ullmann's Encyclopedia of Industrial Chemistry, Wiley-VCH Verlag GmbH \& Co. KGaA, 2000.

[5] http://www.marketsandmarkets.com/PressReleases/polycarb onate-resin.asp, last accessed 03/03/2015.

[6] Antonakou EV, Achilias DS. Recent advances in polycarbonate recycling: a review of degradation methods and their mechanisms. Waste Biomass Valor 2013; 4: 9-21. http://dx.doi.org/10.1007/s12649-012-9159-x

[7] Elmaghor F, Zhang L, Fan R. Recycling of polycarbonate by blending with maleic anhydride grafted ABS. Polymer 2004; 45: 6719-24.

http://dx.doi.org/10.1016/j.polymer.2004.07.022

[8] Tager A, Physical Chemistry of Polymers, Mir, Moscow 1972.

[9] Perrian DD, Armarego WLF and Perrin DR, Purification of Laboratory C,hemicals 2nd Ed, Pergamon Press. New York 1980.

[10] Aly KI, Ahmed RA. Liquid crystalline polymers V. Thermotropic liquid crystalline poly(azomethine-ether)s containing a cycloalkanone moiety in the polymer backbone. Liquid Crystals 2000; 27: 451-8. http://dx.doi.org/10.1080/026782900202633

[11] Andrew SM, Bass RG. Polypyrazolinones from aromatic di(propynoic ester)s and aromatic dihy- drazines. J Polym Sci 1989; 27: 1225-39.

http://dx.doi.org/10.1002/pola.1989.080270410

[12] Al-Muaikel NS, Aly KI, Hussein, MA. Synthesis, characterization and antimicrobial properties of new poly(ether-ketone)s and copoly(ether-ketone)s containing diarylidenecycloalkanone moieties in the main chain. J Appl Polym Sci 2008; 108: 3138-47. http://dx.doi.org/10.1002/app.27963 
[13] Aly KI. New polymer syntheses VIII. Synthesis, characterization and morphology of new unsaturated copolyesters based on dibenzylidenecycloalkanones. Polym Int 1998; 47: 483-90.

http://dx.doi.org/10.1002/(SICl)1097-

0126(199812)47:4<483::AID-PI91>3.0.CO;2-F
[14] Abd-Alla MA, Aly KI, Hammam AS. Arylidene polymers VII. Synthesis and characterization of new polyesters of diarylidenecycloalkanones containing an azo group in the main chain. High Performance Polymers 1989; 1: 323-34.

Received on 15-03-2016

Accepted on 25-03-2016

Published on 19-08-2016

DOI: http://dx.doi.org/10.6000/1929-5995.2016.05.02.3 